\section{Basaltic pillars in collapsed lava-pools on the deep ocean floor}

\section{J. Francheteau*. T. Juteau+ \& C. Rangin*}

- Centre Océanologique de Bretagne. BP 337, 29273, Brest Cedex $\div$ Université Louis Pasteur. Strasbourg

$\ddagger$ Université Pierre et Marie Curie. Paris, France

Observations of peculiar volcanic objects. made by a submersible on the deep sea floor at a depth of about $2.6010 \mathrm{~m}$ at and near the axis of the East Pacific Rise during the CYAMFX expedition as part of the RITA Project' are presented here. Two basic ty pes of flow forms were observed within the crestal area of the East Pacitic Rise: pillow Hows and Huid lavas, the latter sometimes overlying massive Hows. The Fust Pacitic Rise al $21^{\circ} \mathrm{N}$ comprises an axial, unfaulted extrusion zone hordered by an extension zone characterised by faulting ${ }^{2.3}$. Pillow flows occupy the innermost or extrusion zone and constitute small elongated volcanic highs Fluid lavas tend to occur at the edge of the adjacent extension zone in bathymetric lows controlled by normal faults or steep primary slopes of constructional highs. In the $50 \times 200 \mathrm{~m}$ lows which border the extrusion zone the fluid lava is smooth and lobate surfaces which represent the upper surface of the How are locally collapsed and reveal the internal structure of the fluid lavas. Where the roof collapse is extensive. layered columnar features are visible and volcanic layering can be seen against the flank of the hordering volcanic highs (Fig 1-3). Similar features have been reported irom the Galapagos Rift ${ }^{4}$. The diameter of the approximately cylindrical pillars ranges from 0.5 to $2 \mathrm{~m}$. Some pillars are made of multiple coalescent cylinders. The tops of the pillars are glassy. funnelshaped and always widening upuards. The pillars were presumed in he hollow from several observations of gashes or openings in the vertical walls of the pillars. This was demonstrated during dive CY 78-19 to the south where a small pillar was toppled by CYANA and subsequent examination revealed a circular canal along the axis of the pillar. The outer surface of the pillars is marked by centimetre-thick glassy, subhorizontal ledges extending several centimetres from the outer vertical surface of the pillars (Figs $2-4$ ). The ledges are spaced evers $2-5 \mathrm{~cm}$ and show small lava stalactites hanging on the underside of the ledges. Examination of large layered fragments of pillars recovered by CYANA demonstrated that the layering is only a surface feature as it does not extend through the basaltic mass of the pillars. The apparent layering is due to glass ledges adhering to g vertical basaltic pipe. In some rare instances the pillar outer surfuce showed no ledges and instead a imooth surtace corrugated with vertical grooves. Some pillars are

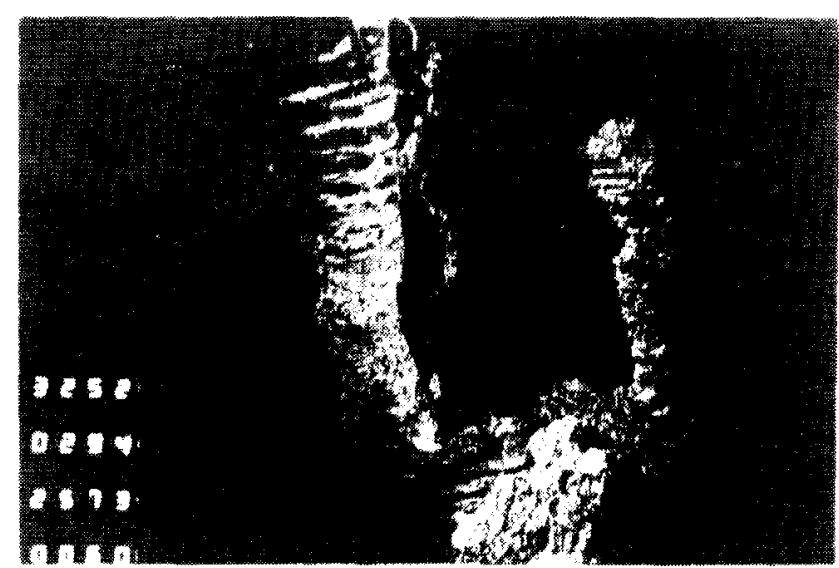

Fig. 1 General landscape: pillars withun coliapsed lava pond. inclined or slightly curved; others get narrower towards the base. The pillars are almost totally aphyric and have the same bulk composition as other lova types recovered in the axial zone of the East Pacific Rise at $21^{\circ} \mathrm{N}$ (ref. 5).

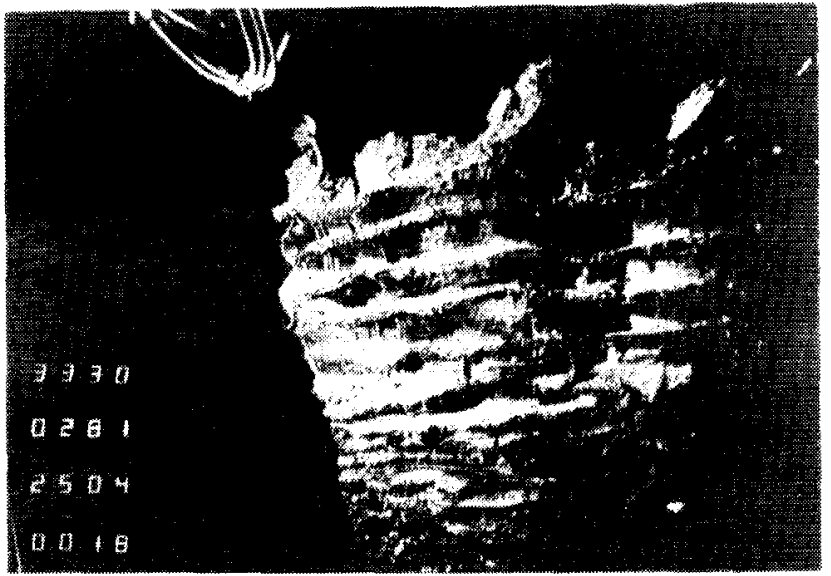

Fig. 2 Detatl of a pillar showing the centimetric pseudo lavering. with thin and darker salient glass layers projecting from the basaltic surface of the pillar.

The pillars occur in forest-like arrangement (Fig. 31. Their spacing ranges from 0.5 to $3 \mathrm{~m}$ and sometimes they coal c. building walls, especially near the edges of the depressions. However, the pillars are not confined to the edges. The flanks of the lows show large segments of undisrupted glass ledge's analogous to those ohserved on the pillar surfaces. In one case idive ( ) $78-19$, where the Huid flows partially tilled a graben. the lavered lateral margin could be seen to represent a chilled. $5-111 \mathrm{~cm}$-thick wall plated against the truncated pillow hasalts of the normal fault scarn. The chilled margin was partiali! detached from the scarp surface.

Non-collapsed glassy upper surfaces of fluid lavas surrounding the tields of pillars show that in the depressions, the thickness of the lobate fluid lava roof is about $111 \mathrm{~cm}$. The horizontil dimension of the lobes is of the same order as the pillar spacing ind pillars provide roof support at the junction hetween adjacent lohes. The geometry of the lobate roof junction is analogous to that of the funnel-shaped pillar tops. Pieces of the lobate roof are commonly preserved around the lluid lavit depressions and also where they form hridges hetween adjacent pillars. In most cases the lava pool appears to be concave upward with a slight (a few metres) depression in the middle of the pool with respect to the edges.

The seatiour around the pillars is strewn hy rubble made up of pillar frayments and roof slahs. A decply incised rille-like cinyon was observed near the axis of the Huid-lava depression.

These observations lead us to the following interpretations Fign 5 and $6 t$ :

(1) The fluid lavas till a preexisting depression either controlled bi taulting or by adjacent constructional high. This is proced hy inspection of the lateral contact and by the contrast in latia freshness between the fill and the adjacent pillows. The remarkable Huidity of the lavas cannot be ascribed to chemical differences or to temperature of extrusion. It probahly reflects the large volume of outpouring which could in turn be a lunction of a very high spreading rate over a short time span.

12 The seawater which is trapped in the crust under the fluid lava pool is heated and expands thy a factor of 20 for a temperature of $\mathrm{x}(11)^{\circ} \mathrm{C}$ at a depth of $2.6010 \mathrm{~m}$ isee ref. $h$ ). forcing Its wals up through the molten lava in a series of vertical conduits (J. Moore, personal communication) (Fig. 5). The walls of the condutts will he quenched at the boundary hetween the rising water and the hutter magma. The conduit walls will grou outward from the inner glassy walls of the conduits with time. This explains the hollow pillars found by CYANA. A similar 


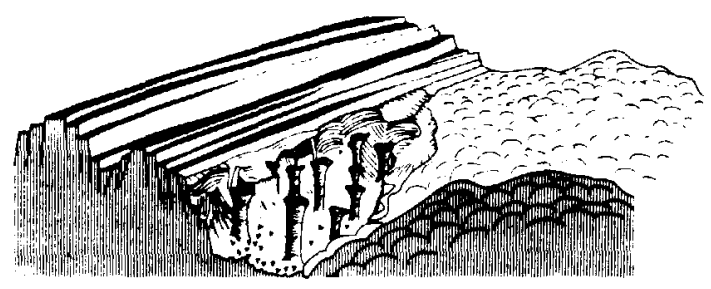

Fig. 3 l.ava pool after roof collapse showing basaltic pillars at the houndary of the unfractured extrusion zone ron the rightl. The pillars are about $10-15 \mathrm{~m}$ high

explanation has been put forward by Fuller ${ }^{7}$ and Waters ${ }^{\wedge}$ to account for the existence of vertical cavities (spiracles) that cut massive lava on the Columbia River Plateau. These authors proposed that water vapour and other gases surge upward into liquid lava that covers marshy ground.

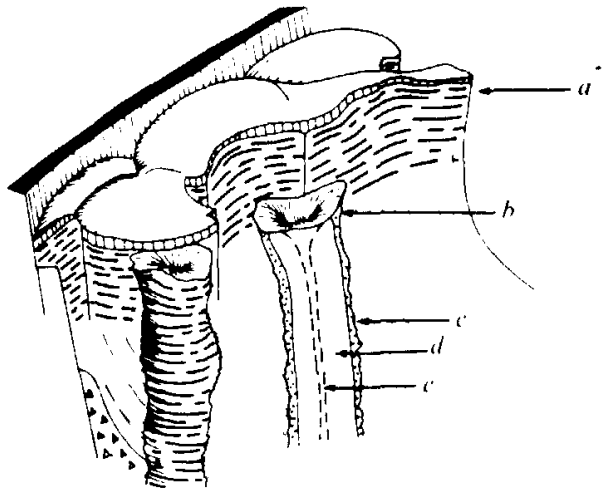

Fig. 4 Detall of hasaltic pillar and of edge of magma pool. a. Pillar attached to the edge of the posl and capped by smooth lobate tlual tav h. hillar: funnel-shaped widening upwards Pillar crosssection showing: $c$, lava cooling ledges on outer margin: $d$, massive las it inside pillar wall: $c$, hollow conduit inside pillar

13 Before anv extensive crystallisation takes place, the lava fool is drained rapidly in successive atages (Fig. 6). This leaves hath-tuh rings around the cold walls present in the depression. This includes the pillars and the edges of the pool. This accounts for the apparent lavering shown by the pillar samples. The rille-like canyon seen on the floor of the pool may be a drain path. Finally down-drag of either the roof or the outer rigid carapace of the pillars can scrape vertical grooves on the still plastic interior and explain the smouth corrugated outer surfaces of some pillars. A similar mechanism has been proposed by Moorc and Richtery to explain the vertical striations on the surtace of Hawaian tree moulds.

(4) Solidification of the fluid lava against the cold wall at the bottom of the pool would help to maintain pillars in position after collapse of the roof.

Thus tall. near vertical and hollow pillars with rings of glassy ledpes are found in dense arrangement within fossil pools of fluid latia. They are interpreted as the fossil witnesses of both

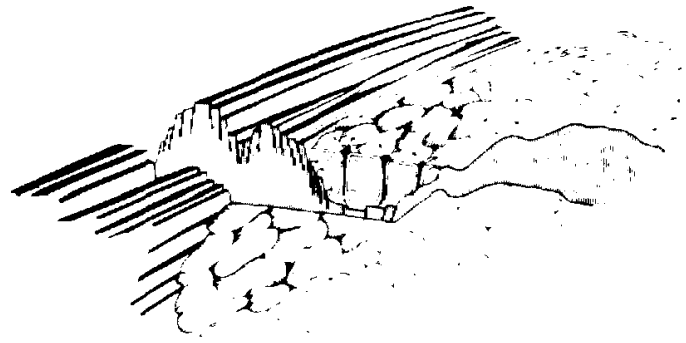

Fig. : Reconstruction of magma pool before the draining of lavas alsi init collapse. The arrows at the pool surface represent escape of water. temporary liquid magma pools which can fill topographic lows and smoth the ridge topography, and of the rhythmic nature and rapidity of the magma pool withdrawal. When drain-off is prevented or when it proceeds too slowly, massive lavas are created.

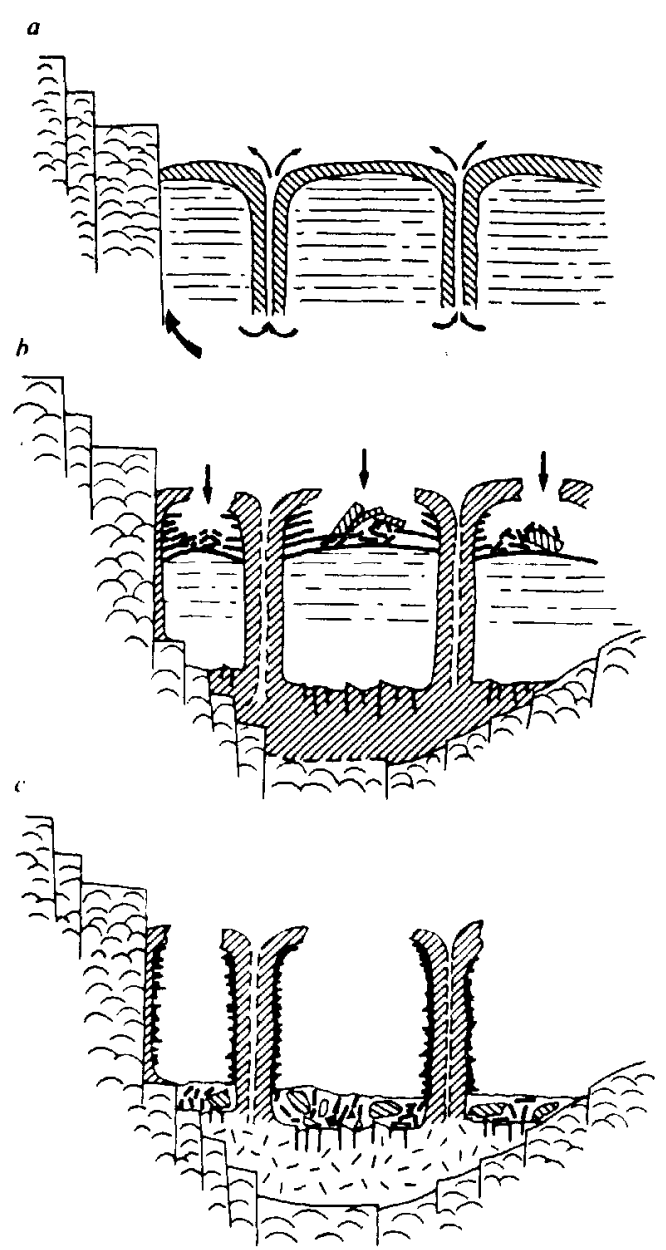

Fig. 6 Inferred evolution of magma pool showing histors a piliars and cooling ledges at several stayes (see text), $a$. Initual staz" of tilling of the depression: $h$, beginning of lava pool withdrawal with concomitant roof collapse. $c$, tinal stage of roof collapse showing isolated pillars standing among coarse rubble.

The fluidity of the lava can be explained if there is ranid emplacement of a large volume of lava resulting in slow cooling of the bulk of the lava pool. The large volume of outpouring mav be due to a high 'instantaneous' spreading rate concomitant with a high ascent rate of the lava.

The observations at $21^{\circ} \mathrm{N}$ show that the size of lava pook increases southward along the axis and thus that the fluid lava regime in the south is predominant over the pillow lava regime. This suggests that instantaneous rates of spreading may be variable along the strike of the mid-ocean ridge.

Receiscil 2- April: accented 30 Jutv 1'77"

CYAMFX Scientific Tcam Foo 59 . 1198 1197

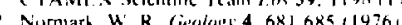

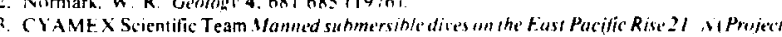
$R / T$ t) in the press).

4. Ballard. R. D. Holcomb. R. T. \& Van Andel. T. H. Sher Fions, Collapse Piri and Law L.t.hes whe Rith latter in the press

S. C) AM11 X Team. Hougaull, H. Cambon. P. \& Eiswen. J. P. Submarine hasalte collected h.

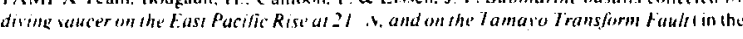
press.

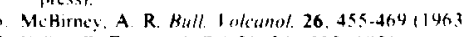

Fuller. R F. tm. J. Sci. 21 . 28!-300(19?11

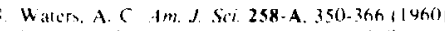

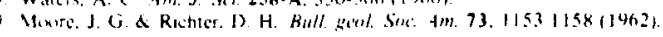

